\title{
Primary care and sex: too close for comfort?
}

\author{
Penny Watson, MRCGP, MFF, General Practitioner Principal, Medical Practitioner in Family Planning and Well Women's \\ Services in Edinburgh, and Family Planning Trainer, Wester Hailes Health Centre, Edinburgh, UK
}

Correspondence: Dr P Watson, Wester Hailes Health Centre, 7 Murrayburn Gate, Edinburgh EH14 2SS, UK. E-mail:pennywatson@blueyonder.co.uk

(Accepted 10th January 2003)

Journal of Family Planning and Reproductive Health Care 2003; 29(2): 44-45

Most general practitioners (GPs) would agree that things sexual are an important part of their patients' lives, so why is it that sexual and reproductive health care is so variable within primary care?

Why is it that the UK, a highly developed country with a socialised health care system with free contraception (but only for women), has such bad sexual health statistics? We have the highest rate for teenage pregnancy in Europe, approximately one in three women receiving a termination in their lifetime, an epidemic of chlamydia in the under-25s, and an estimated $50 \%$ of conceptions unplanned.

Even the new contract for UK GPs ${ }^{1}$ lists contraceptive services as an 'additional' service. What a missed opportunity, to class this and other preventative services as anything other than an absolutely integral part of general practice! They cannot just be neatly categorised and contracted out, important though clinics are for dual service delivery and specialist advice.

Hopefully payment will be adequate to encourage general practices to develop these aspects of their work. If not, many patients will be inconvenienced by lack of easily accessible 'one-stop' services within the practice setting.

How blinkered and short term to consider GPs capable of treating disease (an essential service) without encouraging more consideration of the wider picture.

Undergraduates and registrar GPs receive variable training in sexual and reproductive health dependent mainly on the interests and ethos of their tutors. The membership examination of the Royal College of General Practitioners (MRCGP) does not demand such knowledge of either trainer or registrar and no formal expertise is required of GP principals.

Equally, how can practice nurses, midwives and health visitors, for instance, be fully equipped for their jobs without core training in this area?

There are countless opportunities every working day in general practice to offer help to our patients: $99 \%$ of the population have a GP, averaging three to four consultations per year. It is not just obvious opportunities such as smear taking or the $65 \%$ of all contraceptive work that is done in primary care. Think of impotent diabetic patients, risktaking drug abusers, a depressed homosexual, infertile couples, victims of domestic violence or sexual abuse, stressed mothers in baby clinics, teenagers with acne - for men and women, the list is endless. The overlap between reproductive health and mental health in particular is huge, so children are also often affected.

The Diploma of the Faculty of Family Planning is viewed as desirable training for GPs, and the Faculty has an innovative and visionary structured programme for training and re-accreditation, but where is the GP voice? Not one place is specified for a GP on its council ${ }^{2}$ and Diplomates are represented by one place. The one nominee this year was a gynaecology specialist registrar.

The Sexual Health Strategy for England, whose emphasis seems to lean strongly towards infection control, proposes a stronger role for GPs, but the RCGP has only one representative on this body. ${ }^{3}$

Attitudes need to change! Primary care can deliver so much more cost-effective reproductive health care.

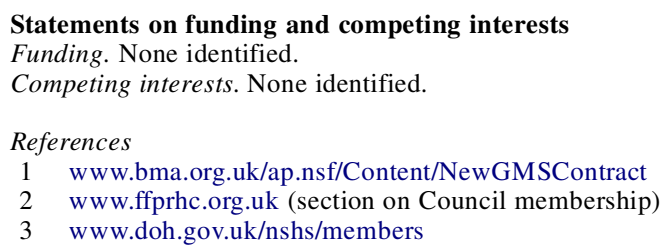

\section{TWENTY-FIVE YEARS AGO: THEN AND NOW}

\section{In search of appropriate contraception: horses for courses}

\author{
Lindsay Edouard, FRCOG, MFFP, International Advisor, Journal of Family Planning and Reproductive Health Care
}

All contraceptive methods are not created equal: to each individual a personal risk, perception, value and choice. Success of a programme depends on a public health approach in the provision of an appropriate mix of options in contraceptive services as an integral part of reproductive health care. A medical practitioner, who had run a family planning service in a developing country, was terribly shocked upon returning to England in the late 1960 s to note that family planning was still 'a very personal subject and not to be discussed'. 'It was not until the mid-1970s that changes in service delivery led to a closing of that gap with developing countries.

An epidemiological analysis demonstrated less risk with various contraceptive methods, as compared to that of pregnancy. ${ }^{2}$ An association of oral contraception with cardiovascular complications had been known, albeit with 'sufficient grounds for thinking that the case against the pill is not yet proven'. ${ }^{3}$ When informed of an increased risk, older women were often reluctant to switch away from their familiarity with oral contraception and the 'expectation of contraceptive security'2 due to its effectiveness. Intrauterine devices (IUDs) already had a 